PONTIFÍCIA UNIVERSIDADE CATÓLICA DO RIO DE JANEIRO

\title{
ESTRATÉGIA DE SEGMENTAÇÃO POR MIX DE PRODUTOS \\ DA OSKLEN
}

Alexandre Kraus de Andrade Nogueira

Trabalho de Conclusão de Curso

CENTRO DE CIÊNCIAS SOCIAIS - CCS

DEPARTAMENTO DE ADMINISTRaÇão

Graduação em Administração de Empresas

Rio de Janeiro, 23 de novembro de 2017. 
Alexandre Kraus de Andrade Nogueira

Estratégia de segmentação por mix de produtos da Osklen

\section{Trabalho de Conclusão de Curso}

Trabalho de Conclusão de Curso, apresentado ao programa de graduação em Administração da PUC-Rio como requisito parcial para a obtenção do titulo de graduação em Administração.

Orientador(a): Marina Frid

Rio de Janeiro, 23 de novembro de 2017. 


\section{Agradecimentos}

À professora Marina Frid, pelo incentivo e apontamentos fundamentais ao longo da monografia, possibilitando assim a criação e conclusão deste trabalho.

Aos professores da faculdade de Administração da PUC-RIO, pelo excelente ensino durante a graduação, motivo pelo qual pude desenvolver meus conhecimentos e utiliza-los na elaboração desta monografia.

Aos meus pais, Gisela Kraus e Sérgio Nogueira por toda dedicação e amor, por confiarem no meu potencial e por terem me criado em torno de princípios necessários para o meu desenvolvimento. A minha irmã Ingrid Kraus, por estar presente nos momentos mais importantes da minha vida e por sempre me apoiar em minhas decisões.

Aos amigos, por todos os conselhos e suportes dados nesses últimos meses. 


\section{Resumo}

Kraus, Alexandre. Estratégia de segmentação por mix de produtos da Osklen. Rio de Janeiro, 2017. 21 páginas. Trabalho de Conclusão de Curso Departamento de Administração. Pontifícia Universidade Católica do Rio de Janeiro.

O presente trabalho tem como objetivo demonstrar um estudo mercadológico realizado pela Osklen, marca de grande relevância no cenário nacional. Tal estudo visa apresentar os aspectos levantados pelos profissionais da Osklen, os quais observaram que alguns pontos de vendas não estavam tendo os resultados esperados. Diante disso, foi elaborado estudo mercadológico para identificação dos produtos que determinados pontos mais vendiam ao longo do dia. Assim, constatou-se que certas praças vendiam determinados produtos em grande escala, enquanto outros detinham a maior parte de suas saídas concentradas em outros produtos. A partir do resultado destas análises, a marca decidiu implementar testes em suas lojas e mudaram o perfil das mesmas, para que essas passassem a atender um perfil de cliente, chamado "collection”. Os resultados dos testes demonstraram não só o aumento de vendas, mas também o crescimento da fidelização de clientes, provando assim que cada cliente prefere frequentar a loja que melhor atende suas necessidades. Com o sucesso da segmentação das lojas por mix de produtos e perfil de clientes, hoje a Osklen atua com três tipos de lojas em todo Brasil, além de possuir filiais em outros cinco países.

Palavras- chave

Osklen; segmentação; produto; mercado-alvo; composto de marketing; cliente. 


\section{Abstract}

Kraus, Alexandre. Osklen product mix targeting strategy. Rio de Janeiro, 2017. 21 pages. Trabalho de Conclusão de Curso - Departamento de Administração. Pontifícia Universidade Católica do Rio de Janeiro.

The purpose of the hereby presented thesis is to showcase a market oriented research done by Osklen, one of the most relevant textile brands in Brazil. Such research aims to discuss the different aspects regarded by professionals at Osklen, who noticed that some of the franchises were not achieving the expected results. In light of this, a market research was conducted in order to point out the products which were sold the most in certain franchises. Based on that, the conclusion was that some stores sold a specific product in large-scale, while other stores had their sales focused on a whole different product. According to these analysis, the brand decided to run tests in their stores and also changed its targeted profile, so these stores would service a specific customer profile called "collection". The tests resulted in a raise in sales, and beyond that, a growth in customer loyalty, proving that each customer has a preference for the store which better fits their needs. Due to the success brought by store segmentation, mixed products and customer profile, Osklen currently acts through three types of stores all around Brazil, in addition to having franchises in five other countries.

Key-words

Osklen; segmentation; product; target market; composed of marketing; client. 


\section{SUMÁRIO}

1. Introdução.............................................................

2. Contexto e a realidade investigada................................... 10

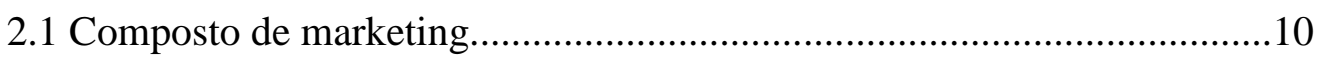

2.2 Mercado Alvo e Nicho de mercado..........................................................12

3. Diagnóstico da situação problema e oportunidade............................................14

4. Análise da situação e proposta de solução.....................................................16

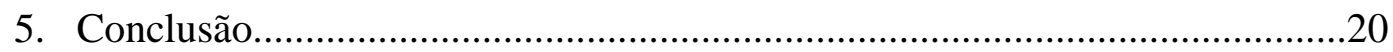

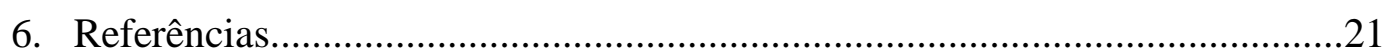




\section{1) INTRODUÇÃO}

Esse trabalho tem como finalidade apresentar um caso relacionado à Osklen, uma das maiores marca de moda do país e sua estratégia mercadológica de segmentação, a partir da introdução de um mix de produtos. Através da identificação das necessidades e desejos do seu público-alvo, será destrinchado um estudo de caso relatando as ações para solução de um problema encontrado em seu método de negócios.

A Osklen foi criada em 1989 pelo ortopedista Oskar Metsavaht. O fundador da empresa, o qual sempre teve um lado artístico, fazia casacos de neve para suas expedições que costumava fazer com uma equipe de médicos. Com o tempo, seus casacos foram fazendo sucesso e encomendas começaram a ser feitas. Assim, deu-se início a marca. A origem de seu nome são as iniciais do nome de seus irmãos Leonardo, Eduardo e sua mulher Nazaré que o ajudaram em toda a trajetória da empresa.

Sua primeira loja da marca foi em Búzios, município pelo qual Oskar é apaixonado. Em seguida, a Osklen abriu a flagship em Ipanema e não parou mais. Atualmente, a marca conta com mais de setenta lojas próprias, além de muitas franquias espalhadas por todo o Brasil. A marca cresceu tanto que hoje representa o Brasil no mercado internacional de moda, tendo lojas em Nova Iorque, Miami, Mikonos, Punta del Este, Buenos Aires e Tóquio.

A empresa tem como missão, "encantar os clientes com nossos produtos, serviço e atendimento, sem esquecer o compromisso socioambiental." Sua visão é: "através do nosso estilo, criatividade e autenticidade nos tornarmos uma marca global, original do Rio de Janeiro." E entre seus valores fundamentai indicam: "criatividade, equilíbrio, sofisticação, despojamento, qualidade, apuro estético, contemporaneidade e sustentabilidade".

A Osklen representa o lifestyle da mulher e do homem modernos, onde convivem o urbano e a natureza, o global e o local, o tecnológico e o orgânico, sempre com estilo e sofisticação. Uma postura expressa em cada viagem realizada por Oskar Metsavaht e em cada expedição apoiada pela Osklen nos quatro cantos do mundo. (Osklen, 2015.) 
A empresa tem um diferencial ideológico em relação ao meio ambiente, realizando várias ações em prol da melhoria contínua do mesmo como a parceria com o Instituto - E, uma associação privada civil sem fins lucrativos que tem como missão transformar e posicionar o Brasil como o país do desenvolvimento humano sustentável. Além disso, o instituto apoia e desenvolve projetos que tenham a ver com seus cinco E's: Earth (Terra), Environment (meio ambiente), Education (educação), Energy (energia), e Empowerment (empoderamento). Em relação à Osklen, o instituto participa do projeto, E-fabrics, que consiste no mapeamento de matérias primas e produtos sustentáveis utilizáveis pela cadeia da moda e pela indústria têxtil em geral. Já são mais de vinte e cinco materiais disponíveis de diversos tipos (látex, jutá, couro de peixe, seda ecológica, etc.). Seus méritos foram reconhecidos pelo SEBRAE, que lhe concedeu o Prêmio Brasilidade por esta pesquisa e iniciativa inovadora, sendo citado pela WWFUK como exemplo a ser seguido pela moda. A marca também desenvolve parcerias com outras empresas como a WWF, Brazil Foundation, UNESCO, ISA, entre outras.

Com todos esses recursos sustentáveis a Osklen acabou lançando um novo segmento no mercado, que é o luxo sustentável. Tal inovação, a fez se destacar no mercado de moda, sendo referência internacional até hoje. Chegou a ganhar um prêmio da UNESCO por conta do trabalho feito com a pele do pirarucu, que é um peixe muito consumido no norte do Brasil. O projeto reutiliza a pele descartada pela indústria alimentícia e a converte em couro, sendo este tão resistente quanto o do bovino. Ela confecciona bolsas, sapatos, mochilas, jaquetas com esse couro.

Tendo em vista os fatos apresentados, se faz de suma importância ressaltar que no ano de 2012 o fundador da Osklen, alienou 30\% da empresa para o grupo Alpargatas. Da mesma forma, no ano de 2014 foram vendidos mais 30\% e assim Oskar Metsavah, fundador da empresa, deixou de ser dono majoritário, tornando-se apenas diretor de criação, cargo que sempre exerceu dentro da estrutura organizacional da marca. Em seguida, a empresa Alpargatas foi vendida para o grupo JBS que por fim, alienou a Alpargatas para o Itaú. 
Diante da instalação de determinada crise de vendas, a marca iniciou um processo de revitalização de sua estratégia e composto de marketing. As lojas que anteriormente se resumiam a apenas um estilo, foram reformuladas para atender os desejos e necessidades de diferentes mercados. Atualmente, cada loja pode conter uma ou mais linhas de produtos, sendo elas classificadas como collection, comercial/casual e a praia.

Assim, o objetivo deste trabalho é analisar a reestruturação da estratégia do composto de marketing da Osklen, entendendo os diferentes públicos-alvo, as distorções de resultado por praça, além de outros fatores importantes para a tomada de decisão. Além disso, ainda serão analisados os resultados desta reestruturação realizada pela maior empresa de moda brasileira. 


\section{2) CONTEXTO E REALIDADE INVESTIGADA}

Para analisar a estratégia mercadológica por trás do sucesso da marca Osklen, torna-se fundamental compreender o papel do marketing e alguns dos importantes conceitos de marketing relacionados a esta marca. Kotler (2000, p 30.) definiu o papel do marketing como:

Processo social do qual pessoas e grupos obtêm aquilo de que necessitam e o que desejam, com a criação, oferta e livre negociação de produtos e serviços de valor com outros.

Assim, objetivando estabelecer um paralelo entre o papel do marketing e suas aplicações no cotidiano de uma empresa, foram coletados materiais institucionais fornecidos pela Osklen e realizadas entrevistas com o diretor comercial, Christian Kos e com o responsável pelo setor de mix de produtos nas lojas, Edvar Gomes.

Além disso, para melhor compreessão do estudo de caso apresentado neste trabalho, as seguintes concepções devem ser aprofundadas para a melhor análise da estratégia da Osklen: mercado alvo (primário e secundário), estratégias de segmentação de mercado e o composto de marketing.

\section{1) Composto de marketing}

De acordo com Kotler e Keller (2006), o composto mercadológico é o que melhor representa os elementos que uma empresa pode e deve controlar. Essas estratégias têm definições baseadas em Produto, Preço, Promoção e Ponto de vendas ou distribuição (Praça), conforme mostra a figura abaixo. 


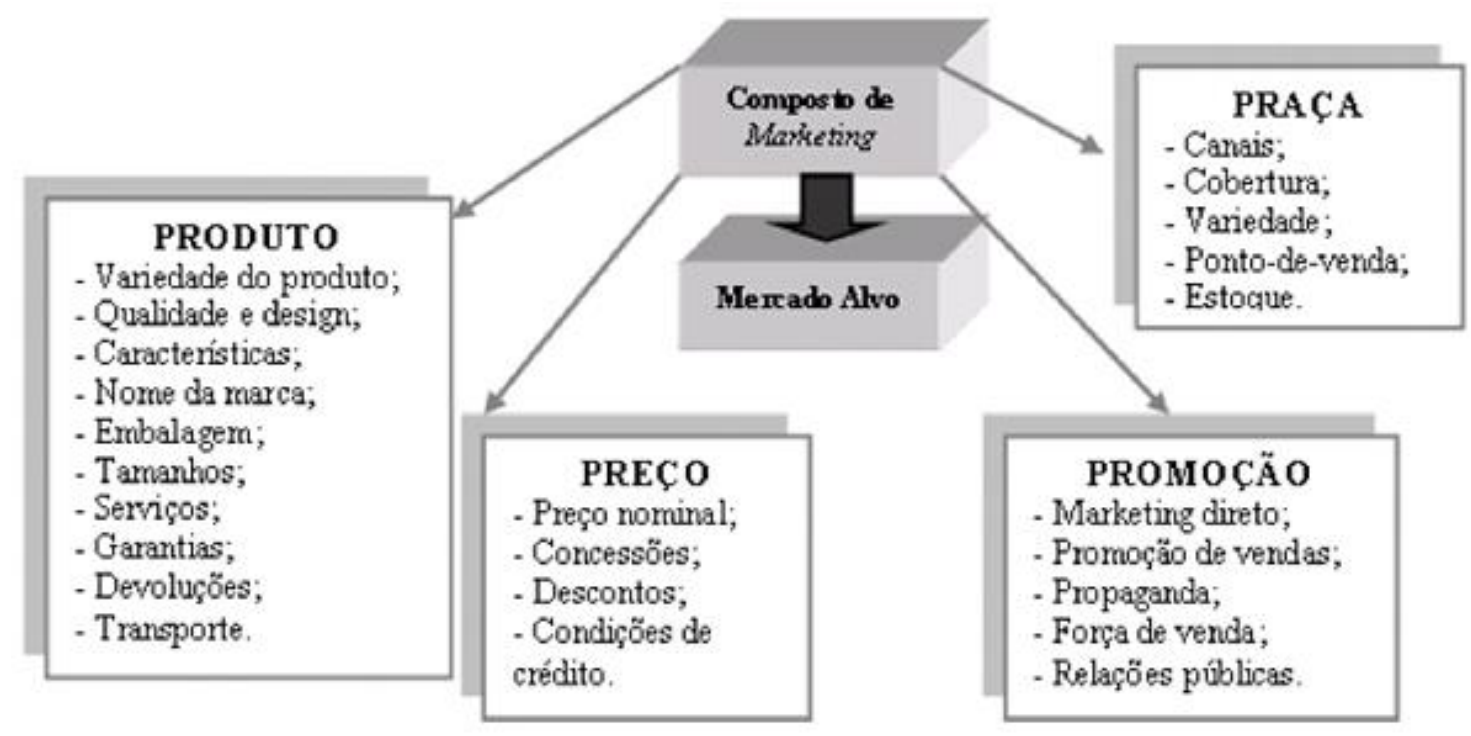

FIGURA 1: Composto de marketing. Fonte: Adaptado de Kotler (2001, p.57.)

Analisando os Quatro P's é possível determinar a importância de cada um deles e sua influência dentro da organização, bem como avaliar as ferramentas que estão sendo utilizadas e tudo que poderá ser feito em termos de estratégias de atuação para desenvolver diferencial estratégico.

a) Composto Produto: Kotler e Keller (2006) afirmam que o produto pode ser definido como tudo o que pode ser oferecido a um mercado para satisfazer uma necessidade ou um desejo, ou seja, bens físicos, serviços, experiências, eventos, pessoas, lugares, propriedades, organizações, informações e ideias.

b) Composto Promoção: O marketing moderno é muito mais do que apenas criar bons produtos e disponibilizá-los ao mercado consumidor, é indispensável neste processo a comunicação com os clientes (KOTLER e KELLER, 2006). Ainda de acordo com os autores, as principais ferramentas do Composto Promoção são: propaganda, promoção de vendas, venda pessoal e relações públicas.

c) Composto Preço: Kotler e Keller (2006) salientam que o preço é o único elemento do composto de marketing que produz receita, os demais produzem custo, os autores avaliam ainda que por meio da determinação do preço uma empresa pode perseguir objetivos que definem estratégias como de sobrevivência, maximização do 
lucro atual, maximização da participação de mercado ou liderança de qualidade de produto. Os itens restantes que tangem o Composto Preço para os quais estão previstos descontos, concessões, condições e prazos de pagamento são igualmente importantes, mas devem levar em consideração principalmente o momento e a circunstância da venda, baseados também em uma realidade de mercado imposta pela concorrência, com o intuito de igualar-se ou criar diferencial competitivo.

d) Composto Ponto de Vendas (Praça): A distribuição pode referir-se ao canal de marketing que corresponde a um sistema de organização pelo qual o produto, recursos ou informações passam de produtores a consumidores, ou pode estar relacionada à distribuição física, que é a movimentação de produtos ou serviços, com local, quantidade e prazos determinados, e que se feita corretamente prioriza a manutenção e otimização de custos. O Ponto de Vendas ou Praça pode ser entendido como a combinação de agentes os quais o produto flui, desde o vendedor inicial (geralmente o fabricante) até o consumidor final. Uma empresa pode, dependendo da logística planejada, utilizar-se do atacadista, do distribuidor, do varejista, do correio, de loja própria, ou de qualquer outro canal para distribuir seus produtos na praça.

\section{2) Mercado Alvo e Nicho de mercado}

Mercado alvo é um grupo específico de consumidores e clientes com desejos e necessidades bem parecidos. Segundo Kotler (2000, p.42), “As empresas têm maiores chances de se saírem bem quando escolhem seus mercados-alvo com cuidado e preparam programas de marketing customizados".

Sendo assim, a Osklen optou por investigar mais profundamente seu público alvo e entender as pequenas e sutis diferenças de necessidades e desejos de seus clientes nas diferentes localidades onde estão suas lojas. Para isso, é necessário entender os nichos de mercado.

Para Kotler (2001), nicho de mercado é um grupo definido mais estritamente, um mercado pequeno cujas necessidades não estão sendo totalmente satisfeitas. Já a segmentação de mercado é o processo de dividir um mercado em grupos de compradores que tenham semelhantes necessidades e desejos, percepções de valores ou comportamentos de compra. Os indivíduos ou organizações de cada grupo - ou 
segmento - do mercado podem responder de maneira semelhante a uma determinada estratégia de marketing. As empresas usam as informações para decidir a quais segmentos de mercado podem atender de forma mais lucrativa, enquanto as organizações sem fins lucrativos usam-nas para serem mais eficientes no alcance de suas metas. O segmento específico de mercado que uma organização seleciona para servir é chamado de mercado-alvo. (CHURCHILL; PETER, 2000.)

Aplicando esse conceito à empresa Osklen e sua análise de públicos para reestruturação de segmentação do publico alvo, nos deparamos com o conceito de marketing de nicho. Segundo Kotler (2000), o marketing de nicho é quando um grupo definido mais estritamente que procura por um mix de benefícios distinto. Em geral, para identificar nichos os profissionais de marketing subdividem um segmento em subsegmento.

Smith (1956) aborda o conceito da seguinte maneira: a segmentação de mercado consiste em ver um mercado heterogêneo, caracterizado por demanda divergente, como um grupo de mercados homogêneos menores em resposta a preferencia por produtos diferentes entre os segmentos importantes do mercado. Isto é um atribuído ao desejo dos consumidores ou usuários por satisfação mais precisa de seus desejos variados.

Sendo assim, a estratégia parte do pressuposto de que os elementos que compõem o mercado não são iguais. Os consumidores são distintos entre si, com comportamentos, desejos e necessidades distintas. O produto, o preço, a promoção e a praça devem ir ao encontro desse consumidor, com necessidades específicas. 


\section{3) DIAGNÓSTICO DA SITUAÇÃO PROBLEMA E OPORTUNIDADE}

Antes de reestruturação da estratégia e segmentação do mix de produtos, alguns pontos de venda com alto potencial, não apresentavam os resultados esperados. Após o entendimento de conceitos importantes, é possível investigar as causas da situação apresentada e diagnosticar o problema a ser atacado.

Desde a sua criação, a Osklen se posicionava como uma marca de produtos de alta qualidade e estilo único. Por isso, seus produtos sempre tiveram um preço elevado em relação aos seus concorrentes diretos e tinham como alvo o público de classe A e B.

Em 2010, com a entrada da Osklen no mercado de luxo, participando dos maiores desfiles de moda do mundo, como NYFW, a marca ganhou novos concorrentes de outras marcas de luxo internacional, como Gucci, Armani, entre outras. Essa nova linha ajudou bastante no processo de segmentação, pois foi possível observar os diferentes desempenhos de vendas nas diferentes lojas.

Tendo em vista os conhecimentos adquiridos referentes aos processos de segmentação, adicionado ao suporte de números sobre o resultado por lojas, ficava cada vez mais claro que algumas lojas não tinham o perfil dos clientes que as frequentavam.

Caminhando no mesmo sentido, o processo de tomada de decisão de compra do consumidor pode ser compreendido como um percurso de etapas. Assim, após a identificação de uma necessidade o mesmo busca a melhor decisão para satisfazê-la. Tendo esse conceito como ponto de partida para a compreensão do estudo, é possível entender que de acordo com Cobra (1997), cada consumidor reage de forma diferente sob estímulos iguais. No entanto, as diferentes reações se encaixam em um mesmo processo decisório de compra.

Com isso, a Osklen observou que possuía três tipos de consumidores dentro do público alvo. O primeiro deles formado pelas classes alta e média-alta. Esses clientes sempre buscavam um tipo de produto e serviço diferenciados. Com um olhar bem mais crítico, este consumidor tem uma percepção mais clara sobre as diferentes qualidades do produto como: tecido de qualidade, uma estampa criativa, e cortes diferenciados. Por isso, estão dispostos a pagar valores mais altos pelo produto e experiência na loja. A loja que atende esse público é a que tem maior ticket médio dos perfis analisados. Em 2016 a loja do segmento collection do Leblon teve um ticket médio de R\$ 914,56 e um P.A (peças por atendimento) de 2,19. Esses números são de grande relevância para o 
perfil de loja, que tende a ter um ticket médio maior que as outras, já que seus produtos são de maior valor.

O segundo tipo de cliente diagnosticado, são os das classes média e média-alta. Tais clientes, apesar de não serem tão distantes social e economicamente do grupo supracitado, possuem grandes diferenças em suas preferências. De modo geral, esses procuram roupas mais cotidianas e preferem utilizar o dinheiro comprando inúmeras peças de roupa ao invés de uma com custo muito elevado. Esse perfil de consumidor costuma comprar mais nas lojas casuais. A loja casual do Leblon teve em 2016 um ticket médio de $\mathrm{R} \$ 607,87$ e um P.A de 3,12. Esses números demonstram o perfil de compra de cada tipo de cliente. O casual compra mais peças e mais baratos e o collection compra menos peças, mas com preços mais elevados. Segundo Solomon (2010) a necessidade de consumir é inerente a todos os indivíduos e faz parte do dia a dia de qualquer um.

Por último, mas não menos importante, encontram-se os clientes estrangeiros. A marca é a primeira brasileira a ter lojas em vários países e é bastante conhecida e reconhecida internacionalmente. Ainda assim, dentro do grupo de estrangeiros, existem dois tipos de perfis: o mais "popular", que busca peças relacionadas ao Rio de Janeiro e temas inspirados na cultura brasileira, ou aqueles com alto poder aquisitivo e que estão acostumados com os altos padrões de luxo do mercado internacional, comprando os itens mais caros e valiosos da loja, como as peças exclusivas com materiais diferenciados e utilizados em desfiles oficiais da marca. 


\section{4) ANÁLISE DA SITUAÇÃO E PROPOSTA DE SOLUÇÃo}

$\mathrm{Na}$ análise da estratégia a empresa reparou que as suas lojas eram muito parecidas. Características como por exemplo, iluminação, exposição de produtos, vitrine, perfil da equipe, e principalmente os produtos em si não tinham diferenciação por praça

Por ter uma coleção de produtos muito vasta, não há como expor todos os produtos da coleção em apenas uma única loja. Posto isso, a Osklen percebeu algumas oportunidades de melhoria. Segmentar as lojas de acordo com o perfil de cliente, ou mercado alvo primário, que as frequentam, era uma decisão que poderia maximizar as vendas e a satisfação dos seus clientes.

Assim, apesar de todas exibirem a marca na fachada, foram criados três tipos de lojas Osklen com pequenas diferenças.

- Osklen Collection - é uma loja voltada para um público mais selecionado, com peças de desfile, alta costura e tecidos nobres, além de ter como especialidade a venda do couro de pirarucu, que é usado para fazer bolsas, tênis e mochilas. Um conceito de moda que revolucionou o mercado de moda mundial, o luxo sustentável.

Nesta loja, os vendedores devem ser estudantes, poliglotas, com um perfil de funcionários que tivessem preparados a lidar com publico exigente que suas lojas concentram. Situadas nos melhores pontos de venda da cidade como Leblon, Ipanema, Copacabana e Barra da Tijuca, lugares onde tem grande luxo de estrangeiros e clientes com alto potencial. Clientes esses, que tem uma percepção diferente na experiência de compra, que fazem questão de receber um serviço diferenciado. Nessas lojas os vendedores são treinados a fazer um atendimento diferenciado, por ser outro tipo de abordagem. Esses clientes gostam de ser cortejado, ouvir dicas de composição, saber das novidades. Por ser um atendimento de característica demorada, nessas lojas são servidos cafés e chás e costumam ter um número de peças nas araras menor que o das outras, para valorizar o produto exposto. Além de vender os produtos mais selecionados da coleção. 


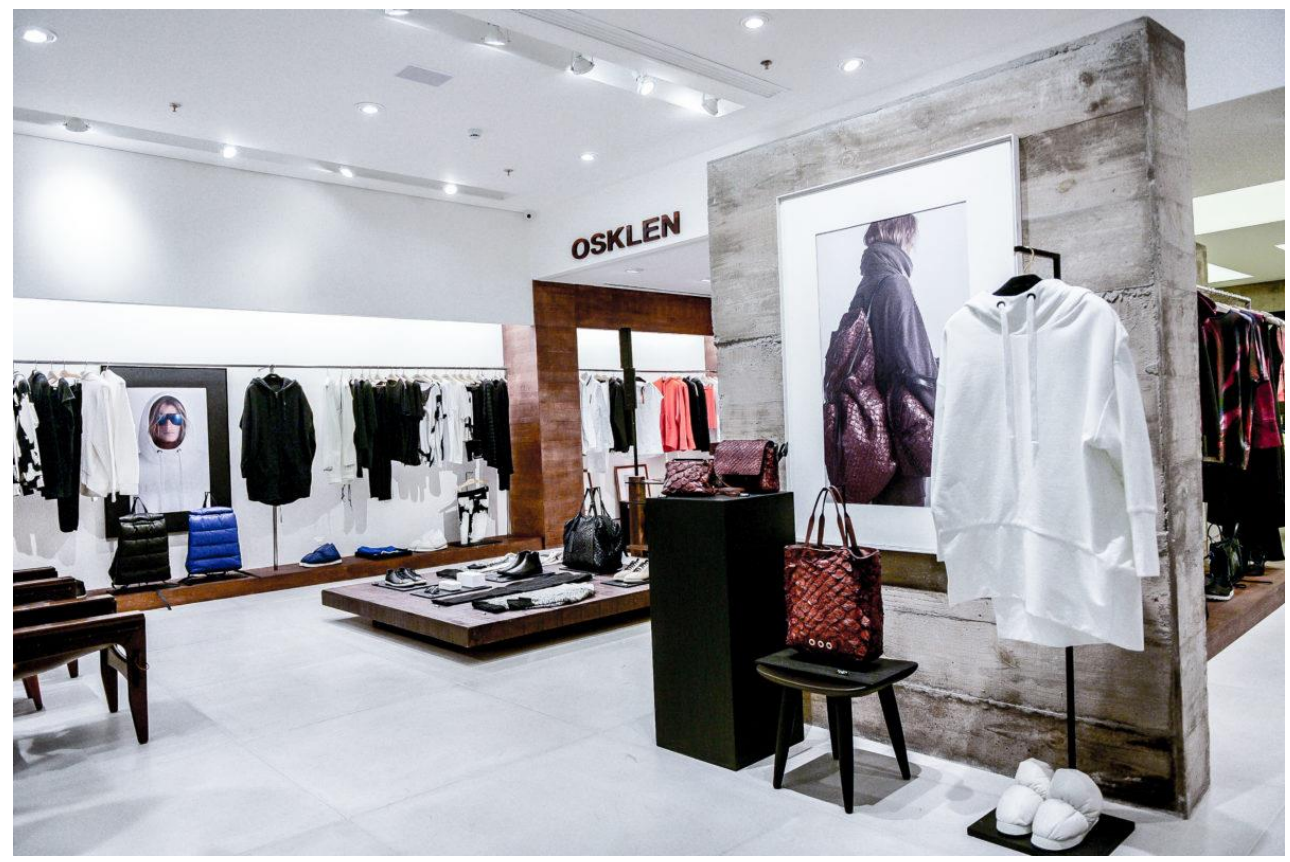

FIGURA 2: Loja da Osklen Collection no Iguatemi SP. Fonte:

http://ffw.uol.com.br/lifestyle/gente/osklen-reabre-loja-no-iguatemi-sp-com-previa-dofilme-soundtrack/)

- Osklen Comercial/Casual - o próprio nome já diz, é uma loja mais voltada para o dia a dia, T-shirts, bermudas, calças jeans, tanto masculinas quanto femininas. Esse é um conceito de loja mais comum pelo Brasil.

Estas lojas também a se encontram nos melhores pontos e alguns pontos de massa, como o Barra Shopping. São lojas com mais produtos, normalmente maiores e que recebem maior fluxo de clientes. Os vendedores precisar ter como característica a agilidade, pois atendem um grande número de clientes por dia. Pessoas com o perfil de comprar maior quantidade de peças e não passar muito tempo em loja. 


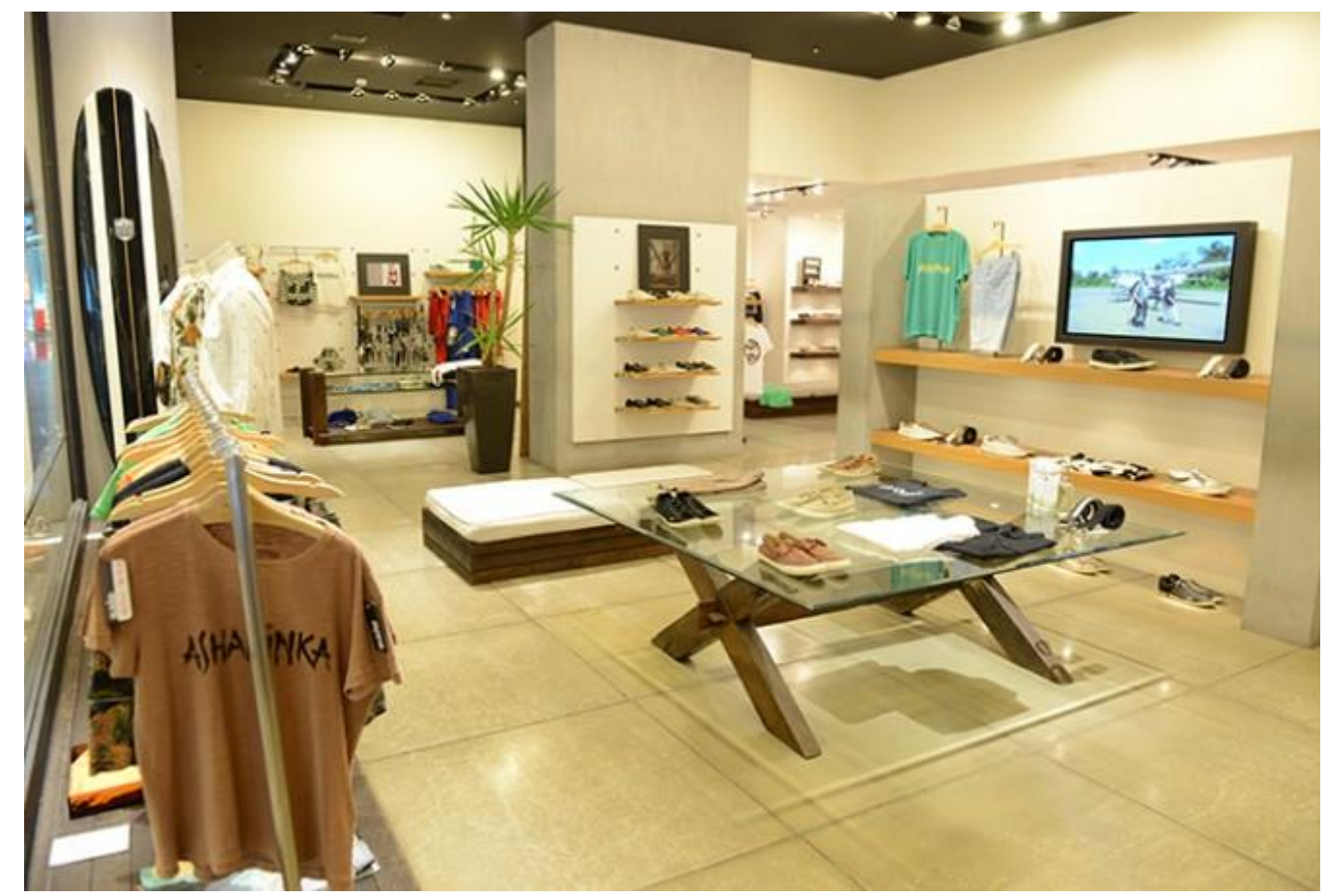

FIGURA 3: Loja da Osklen Casual no Shopping Anália Franco SP. Fonte: (http://www.shoppinganaliafranco.com.br/lojas/osklen)

- Osklen Praia- é a loja que é verão o ano todo, tendo a moda praia como principal coleção, é uma loja mais procurada por estrangeiros, que quando vem ao Brasil, querem uma lembrança de algo tropical.

Situadas no Arpoador e em Ipanema, são lojas que a coleção de verão se estende o ano todo. Ela não acompanha as coleções de estação como as outras lojas . Seus vendedores são treinados para lidar basicamente com estrangeiros, já que são principais clientes desse tipo de loja. Essas lojas são as de menor faturamento, elas servem mais como lojas conceito, que mantem a imagem da marca para os consumidores de fora do país, que sempre estão a procura de roupas de tropicais. 




FIGURA 4: Loja da Osklen Surfing na Galaria River RJ. Fonte: (https://br.pinterest.com/pin/573364596286422651/?lp=true) 


\section{5) CONCLUSÃO}

O estudo apresentado no presente trabalho teve como finalidade apresentar um caso relacionado à estratégia de marketing de uma das maiores marcas de moda do país: A Osklen. O exercício foi realizado a partir da compreensão de alguns conceitos chaves de marketing, como composto de marketing e segmentação por mix de produtos, e aplicado à realidade da Osklen em um momento de reestruturação de estratégia.

A necessidade de mudança surgiu após a identificação de um problema relacionado ao seu público al vo primário. A partir desse gatilho, foi realizada uma investigação com relação ao seu público alvo e, consequentemente encontrada oportunidades de melhoria para atender aos desejos e necessidades do público alvo.

$\mathrm{O}$ caso permitiu correlacionar às estratégias mercadológicas práticas utilizadas pela Osklen com as teorias aprendidas ao longo do curso de Administração e seus princípios de maximização do lucro. Além disso, o case é valioso, pois foi bemsucedido e marcou uma nova era da empresa.

Entretanto, o sucesso do trabalho apresentado fica ainda mais claro se compararmos o valor vendido por loja antes e depois da reestruturação da estratégia. No entanto, por uma questão de confidencialidade de informações da empresa em questão, os números não foram divulgados. Ainda assim, a sugestão de análise desses números para uma futura evolução da pesquisa seria valiosa para complementar a tese.

Por último, o tema foi importante para demonstrar a relevância da melhor adequação do composto de marketing (produto, preço, praça e promoção) ao seu público alvo. A partir da feitura do trabalho, foi possível aprofundar e entender tais conceitos que são valiosos para o crescimento e sucesso das marcas em qualquer setor do mercado. 


\section{6) REFERÊENIAS}

KOTLER, Philip. Administração de Marketing. 12 ed. São Paulo: Pearson, 2000

KOTLER, Philip; KELlER, Kevin Lane. Administração de Marketing. 12 ed. São Paulo: Pearson, 2006

MITH, W.R. Product differenciation and market segmentation as alternative marketing strategies. Journal of Marketing, Ann Arbor,MI, v.21, p.3-12, Julho, 1956.

SOLOMON, Michael R. O Comportamento do Consumidor: Comprando, Possuindo e Sendo. 11 ed. Porto Alegre: Bookman. 2016.

CHIAVENATO, Idalberto. Administração dos novos tempos. $2^{\mathrm{a}}$ edição, $8^{\mathrm{a}}$ tiragem. São Paulo: Elsevier Editra Ltda, 2005

COBRA, M. Marketing básico: uma perspectiva brasileira. 4a edição São Paulo: Atlas, 1997

DURVAL, Rodrigo. Comportamento do consumidor e decisão de compra. Disponível em <http://www.administradores.com.br/artigos/academico/marke-comportamento-doconsumidor-e-decisao-de-compra/74801/>. Acessado em 20 de setembro de 2017.

Disponível em <www.osklen.com.br>. Acessado em 20 de semtebro de 2017. 